\title{
Characterization of Thyroid Nodule by Sonographic Features
}

\author{
Khadka $H^{1}$, Sharma $S^{1}$, Ghimire RK$^{2}$, Sayami $G^{3}$ \\ ${ }^{1}$ Department of Radiology, Bir Hospital(NAMS) \\ ${ }^{2}$ Dept of Radiology,TUTH \\ ${ }^{3}$ Dept of pathology,TUTH.
}

Received: January 15, 2016

Accepted: May 20, 2016

Cite this paper

Khadka H, Sharma S, Ghimire RK, Sayami G. Characterization Of Thyroid Nodule By Sonographic Features. Nepalese Journal of Radiology 2017;7(10):19-26.

\begin{abstract}
Introduction: The thyroid is an endocrine gland situated in the infrahyoid compartment of neck in a space outlined by muscle, trachea, esophagus, carotid arteries and jugular veins. Though nodular thyroid disease is relatively common, thyroid cancer is rare and accounts for less than $1 \%$ of all malignancies indicating that overwhelming majority of thyroid nodules are benign. ${ }^{1}$ The purpose of this study was to assess the sonographic characteristics in a solitary thyroid nodule and predict risk of malignancy.
\end{abstract}

Methods: This prospective study was conducted in a tertiary care hospital in Kathmandu. Sixty two patients with palpable thyroid nodule were evaluated for sonographic characteristics .USG guided FNA for cytopathological examination was then performed.

Results: Out of 66 patients, four were subsequently excluded because they didn't fulfill the inclusion criteria.

Of the 62 patients, 47 (75.8\%) were females and 15 (24.2\%) were males. Among 56 benign nodules, 45 $(80.4 \%)$ were in females and 11(19.6) were in male. Among 6 malignant nodules, $4(66.7 \%)$ were in males and $2(33.3 \%)$ were in females.

Result shows 5 malignant nodules $(83.3 \%)$ were solid where as 1 malignant nodule $(16.7 \%)$ was complex with solid predominance. All 4 cystic nodules $(7.1 \%)$ were benign. All complex nodules with predomint cystic components were also benign.

One malignant nodule (16.7\%) had snow storm type of microcalcification. None of the benign nodules had microcalcification. Nodule having microcalcification was malignant.

Findings showed that all malignant nodules $(100 \%)$ had increased internal vascularity whereas benign nodules were variable in internal vascularity.

Conclusion: This study has shown that colloid goiter is the commonest benign diagnosis whereas papillary carcinoma is the commonest malignancy. Malignant nodules are solid or predominantly solid whereas cystic and predominantly cystic nodules are likely to be benign. Macrocalcification and internal vascularity are not reliable to differentiate benign from malignant nodule. However, snowstorm calcification makes a nodule likely to be malignant whereas egg shell calcification is characteristic for benign nodule.

Key words: Fine needle aspiration, Thyroid nodule, Ultrasonography

Correspondence to: Dr Hensan Khadka

Associate professor Bir Hospital(NAMS)

Email: hensankhadka@yahoo.com

Licensed under CC BY 4.0 International License which permits use, distribution and reproduction in any medium, provided the original work is properly cited 


\section{INTRODUCTION}

Thyroid is an endocrine gland. It lies against C5 to T1 vertebral levels. ${ }^{1} 4-7 \%$ of adult population has palpable thyroid nodule., 2,3 Exposure to ionizing radiation increases the incidence. ${ }^{4,5}$ In autopsy $50 \%$ adults $>60 \mathrm{y}$ have thyroid nodule. ${ }^{6}$ Thyroid cancer is however rare and accounts for less than $1 \%$ of all malignancies. $^{7}$

About $80 \%$ of nodular thyroid disease is due to hyperplasia of the gland. ${ }^{8}$ Many cystic thyroid lesions are hyperplasic nodules having liquefactive degeneration. In the course, calcification, which is often coarse may occur., ${ }^{9}$ Though initially isoechoic, as the size of the mass increases, it may become hyperechoic, owing to the numerous interfaces between cells and colloid substance., ${ }^{9,11}$ The approximate prevalence of malignant nodule sare: Papillary carcinoma $75-90 \%$ 7,12, Follicular carcinoma 5-15\% ${ }^{7}$, Medullary carcinoma 5\%, Lymphoma 4\% and Anaplastic carcinoma $<2 \% .{ }^{13}$

Of these, papillary and follicular carcinomas have best prognosis whereas anaplastic carcinoma has worst prognosis. ${ }^{14}$ Other indicators of poor prognosis are male sex and age $<20$ years or $>65$ years. ${ }^{15}$ Papillary carcinoma is a predominant histologic type in those who had previous radiation exposure $(85-90 \%) .{ }^{16}$ High iodine intake predisposes to papillary carcinoma but follicular carcinoma is more common in area with low iodine content. ${ }^{17}$ It has been previously thought that most papillary carcinoma of thyroid less than $10 \mathrm{~mm}$ in maximal diameter have low risk of metastases. ${ }^{18,19}$ But occult papillary carcinoma of the thyroid as small as $2 \mathrm{~mm}$ has been shown in some studies to have already metastasized to cervical nodes. ${ }^{18-21}$

The purpose of this study was to assess the sonographic characteristics in a solitary thyroid nodule and predict risk of malignancy.

\section{METHODS}

It was a prospective study carried out in a tertiary care hospital. Patients with solitary thyroid nodule referred for US evaluation were studied. USG of the neck was carried out with 7.5 MHZ probe. The nodules were interpreted with respect to vascularity, echostructure and calcification. Under sonographic guidance, FNA was performed by using $23 \mathrm{G}$ needle with standard technique using suction aspiration and slides sent for cytological evaluation. The specific diagnosis for each case was confirmed by cytologic examinations. Statistical analysis was performed using SPSS software version 10.0 and statistical calculations were performed with Chi square, Fisher exact and independent samples $t$ tests.

Data associations were considered statistically significant at $\mathrm{P}<0.005$.

\section{RESULTS}

Out of 66 patients, four were subsequently excluded because they didn't fulfill the inclusion criteria. The sonographic features of all nodules were obtained by high resolution USG and FNA was subsequently performed in all of them. Specimens were immediately sent for cytology examination. FNA was considered gold standard.

Of the 62 patients, $47(75.8 \%)$ were females and $15(24.2 \%)$ were males. Among 56 benign nodules, $45(80.4 \%)$ were in Females and 11(19.6) were in male. Among 6 malignant nodules, $4(66.7 \%)$ were in males and $2(33.3 \%)$ were in females.

Result shows 5 malignant nodules $(83.3 \%$ ) were solid whereas 1 malignant nodule $(16.7 \%)$ was complex with solid predominance. All 4 cystic nodules $(7.1 \%)$ were benign. All complex nodules with predomint cystic components were also benign.

One malignant nodule (16.7\%) had snow storm type of microcalcification. None of the benign 
nodules had microcalcification. Nodule having microcalcification was malignant.

Findings showed that all malignant nodules $(100 \%)$ had increased internal vascularity whereas benign nodules were variable in internal vascularity.

Hence, validity of these parameters was tested and the results are given below:

\section{Table 1: Distribution Of Internal Vascularity In Benign Vs Malignant Nodules}

\begin{tabular}{|c|c|c|c|c|}
\hline & & & ur type & Total \\
\hline & & Benign & Malignant & \\
\hline Internal vascularity & Nil & 27 & & 27 \\
\hline & & $48.2 \%$ & & $43.5 \%$ \\
\hline & $<25 \%$ & 20 & 6 & 26 \\
\hline & & $35.7 \%$ & $100.0 \%$ & $41.9 \%$ \\
\hline & $26-50 \%$ & 7 & & 7 \\
\hline & & $12.5 \%$ & & $11.3 \%$ \\
\hline & $51-75 \%$ & 2 & & 2 \\
\hline & & $3.6 \%$ & & $3.2 \%$ \\
\hline Total & & 56 & 6 & 62 \\
\hline & & $100.0 \%$ & $100.0 \%$ & $100.0 \%$ \\
\hline
\end{tabular}

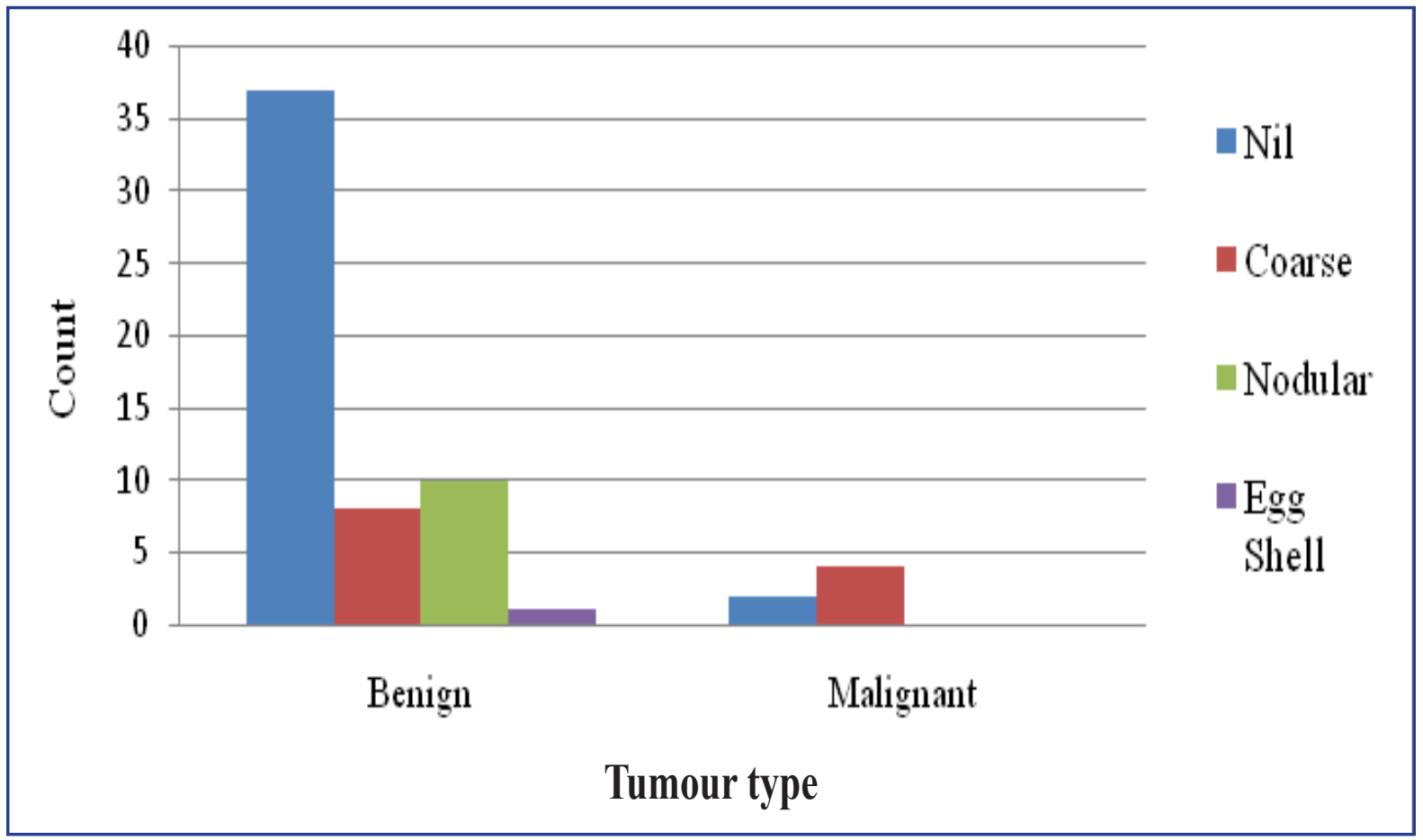

Figure 1: Distribution Of Macrocalcification In Benign Vs Malignant Nodules 


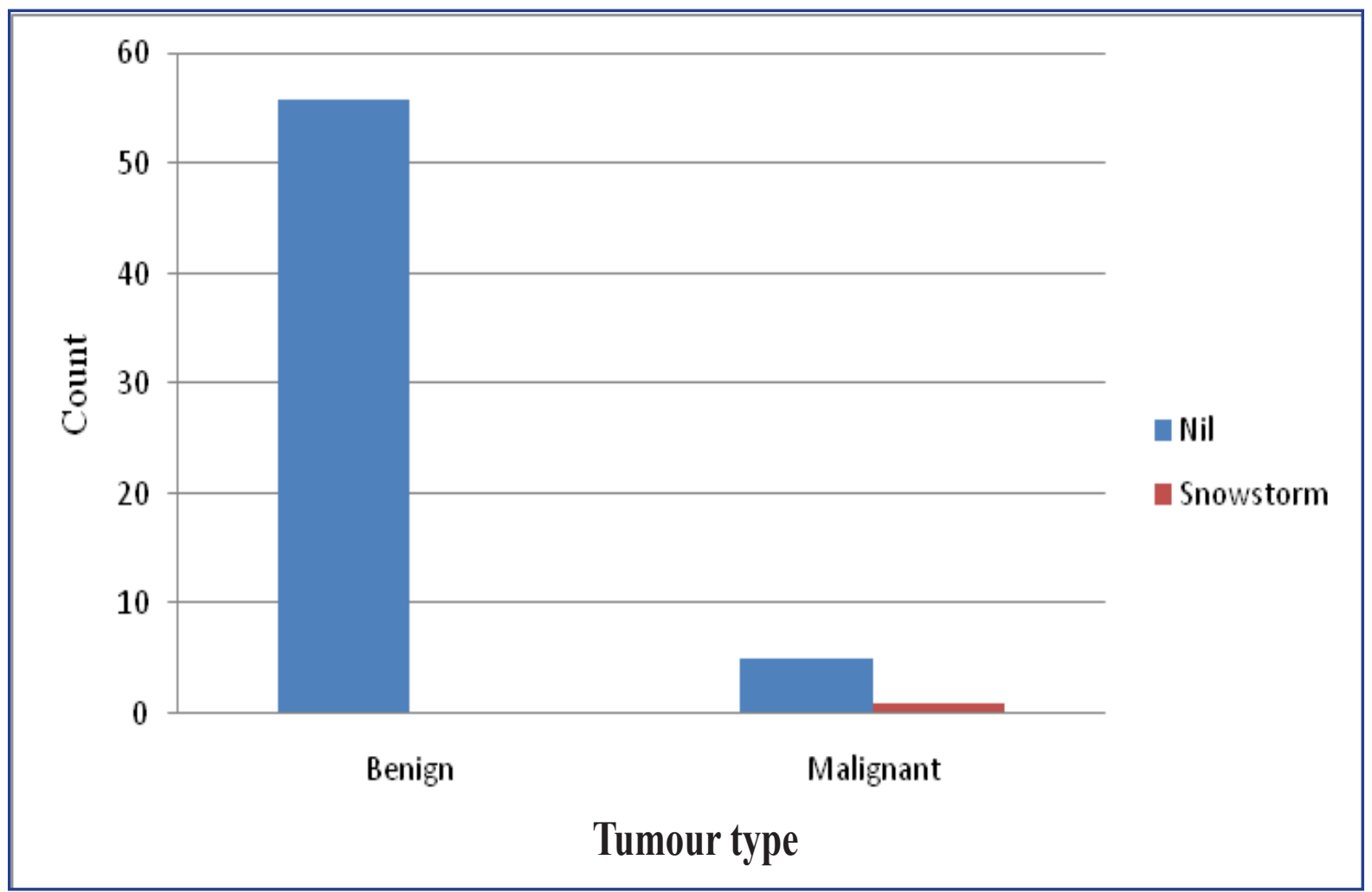

Figure 2: Distribution Of Microcalcification In Benign Vs Malignant Nodules

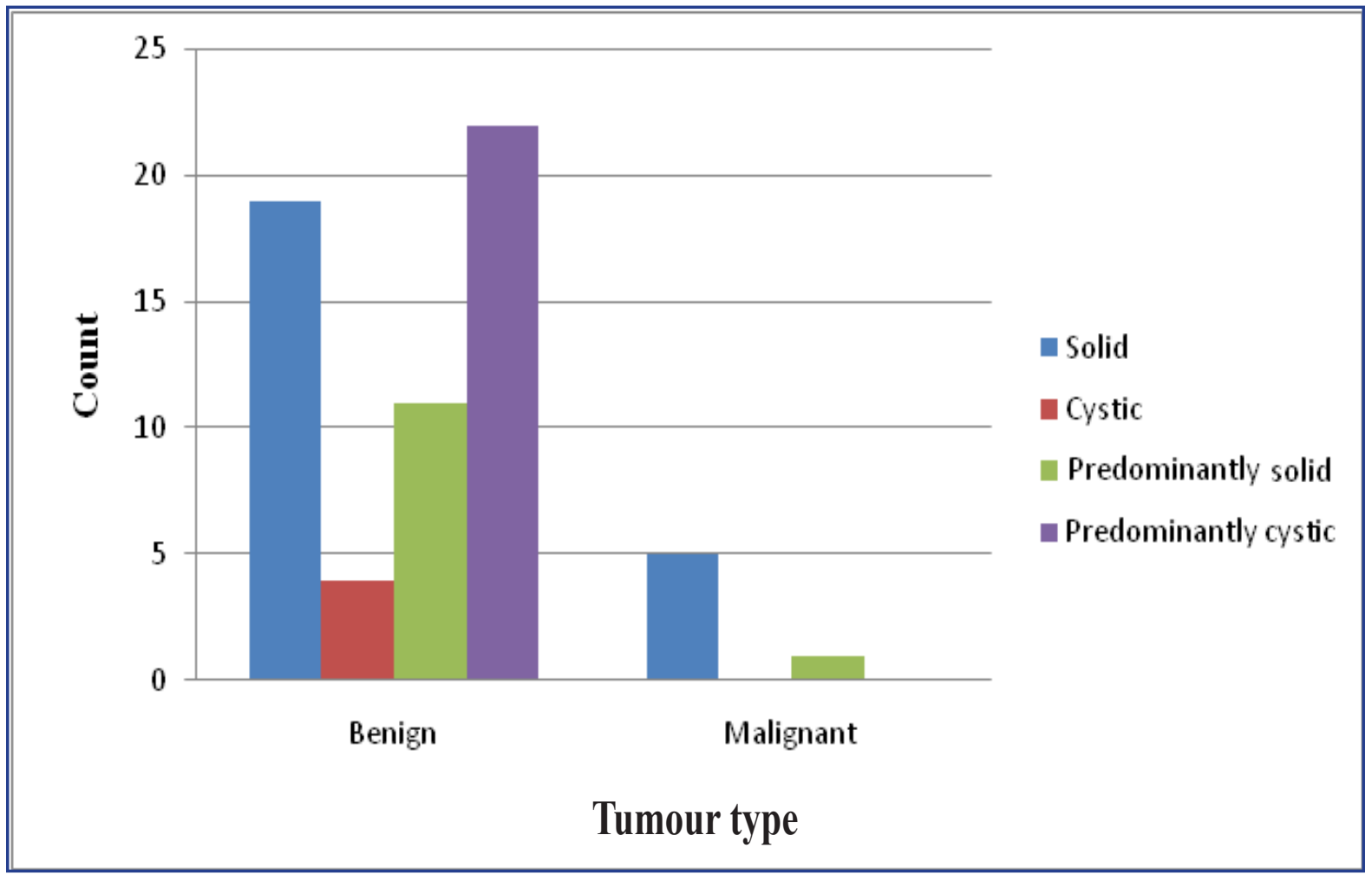

Figure 3: Distribution Of Internal Echotexture In Benign Vs Malignant Nodules 
Table 2: FNAC Diagnosis

\begin{tabular}{|l|l|l|} 
Diagnosis & $\begin{array}{l}\text { F r e - } \\
\text { quency }\end{array}$ & $\begin{array}{l}\text { e r - } \\
\text { cent }\end{array}$ \\
\hline Colloid goiter & 50 & 75.8 \\
\hline Nodular goiter & 4 & 6.1 \\
\hline Papillary carcinoma & 5 & 7.6 \\
\hline Suspicious malignancy & 1 & 1.5 \\
\hline Acute thyroiditis & 1 & 1.5 \\
\hline Abscess & 1 & 1.5 \\
\hline Follicular carcinoma & 1 & 1.5 \\
\hline Follicular adenoma & 1 & 1.5 \\
\hline Dequervain's thyroiditis & 1 & 1.5 \\
\hline No definite opinion & 1 & 1.5 \\
\hline Total & 66 & 100.0 \\
\hline
\end{tabular}

\section{DISCUSSION}

Evaluation of thyroid nodule frequently involves a stepwise performance of clinical evaluation to several imaging techniques. The use of USG in the assessment of nodular thyroid disease has greatly increased the detection rate of small thyroid nodules. ${ }^{20}$ Evaluation of thyroid nodule by FNA has been the gold standard. The overall accuracy of FNA exceeds $95 \%$, therefore it is currently the most accurate and cost effective method for initial evaluation of nodular thyroid disease. As thyroid nodule is shown by USG in $30-50 \%$ of general population and less than $5-6.5 \%$ of these are malignant ${ }^{20}$, subjecting every patient with thyroid nodule to invasive procedure (FNA) would be a costlier venture. Evaluation of thyroid nodule primarily by FNA is common in North America and Northern Europe. In other European countries and Japan where goiter has a very high prevalence, the initial evaluation relies on radionuclide and sonographic imaging, owing to the need to select those nodules that must undergo FNA. ${ }^{1}$

In this study 66 patients from different parts of the country were studied by their sonographic characteristics including color Doppler. Four patients were subsequently excluded making total cases of 62 for further analysis. Each characteristic was evaluated individually and in combination to determine sensitivity, specificity, positive predictive value and negative predictive value in a malignant nodule. They were then subjected for FNA. Specimen was immediately sent for cytopathologic study.

Out of 62, 56 nodules $(90.4 \%)$ were benign and 6 nodules $(9.6 \%)$ were malignant.

The prevalence of malignant nodule in this study resembles to the prevalence as shown by the study of Enrico papini et al ${ }^{20}(9.2 \%)$. $47(75.8 \%)$ were female and $15(24.2 \%)$ were male. Among 56 benign nodules, 45 (80.4\%) were in females and 11(19.6) were in male. Among 6 malignant nodules, 4(66.7\%) were in males and $2(33.3 \%)$ were in females.

The mean size of benign and malignant nodules was $3.04 \mathrm{~cm}$ (SD 1.29) and $3.00 \mathrm{~cm}$ (SD 0.89) respectively with no significant difference. The largest size group was $2-3 \mathrm{~cm}$ in benign nodules $(23,41.1 \%)$. Malignant nodules had the size range of $1-4 \mathrm{~cm}$.

The mean age of patient with benign and malignant nodules was 47.93 years (SD 13.15) and 48.06 years (SD 13.09) with no significant difference.

The most common benign nodule was colloid goiter $(50$ of $56,89.2 \%$ ) with or without degeneration and most common malignant nodule was papillary carcinoma, ( 5 of $6,83.3 \%$ ). These figures resemble to the prevalence of $80 \%$ of colloid goiter. The prevalence of papillary carcinoma also closely resembles to the general prevalence of papillary carcinoma of $75 \%-90 \% .^{7,12}$

In this study the sonographic characteristics of the nodule were studied according to internal echostructure (solid, cystic, predominantly solid and predominantly cystic), presence or absence of calcification (macrocalcification and microcalcification) and intranodular vascularity (no color flow, $<25 \%, 26-50 \%, 51$ $75 \%$ and $>75 \%$ ). The cytopathologic finding was regarded as either benign or malignant. 


\section{EVALUATION OF ECHOSTRUCTURE}

In this study 5 malignant nodules $(83.3 \%)$ were solid whereas 1 malignant nodule(16.7\%) was complex with solid predominance.

Solid echostructure as a single parameter, had sensitivity, specificity, positive predictive value and negative predictive value of $83.3 \%$, $66.1 \%, 20.8 \%$ and $97.4 \%$ respectively to predict malignancy, with $\mathrm{P}$ value of 0.028 but after performing binomial logistic regression analysis $P$ value increased to 0.135 . This result is close to the study by Enrico papini et al ${ }^{20}$ which showed $87 \%$ of the malignant nodules which were solid and hypoechoic.

Study by Jason D.Janniculi et al ${ }^{22}$ showed most of the malignant nodules were predominantly solid $(85.3 \%)$ or mostly solid with cystic regions $(11.8 \%)$.

This result contradicts to the study performed by Mary C.Frates et al ${ }^{23}$ which showed 13 of 32 malignant nodules $(40.1 \%)$ to be solid. All the 4 cystic nodules $(7.1 \%)$ were benign. All nodules with predominantly cystic components were also benign (P-value: 0.101).

\section{EVALUATION OF CALCIFICATION}

This study showed that none of the benign nodules had microcalcification. 1 malignant nodule $(16.7 \%)$ had snow storm type of microcalcification. Nodule having microcalcification was malignant (P-value: 0.097). However this result was statistically insignificant. Eighteen benign nodules $(32.2 \%)$ and 4 malignant nodules (66.7\%) had macrocalcification. All macrocalcification in malignant nodules were coarse. Macrocalcification was not present in 37 benign nodules $(66.1 \%)$ and 2 malignant nodules $(33.3 \%)$. So 5 of $6(83.4 \%)$ malignant nodules had calcification. Taking coarse macrocalcification as a single parameter, it had sensitivity, specificity, positive predictive value and negative predictive value of $66.7 \%$, $85.8 \%, 33.3 \%$ and $100 \%$ respectively to predict malignancy with $\mathrm{P}$ value of 0.011 . But after binomial logistic regression analysis, $\mathrm{P}$ value was 0.051 . Snow storm microcalcification as a single parameter to predict malignancy, it had sensitivity, specificity, positive predictive value and negative predictive value of $83.3 \%, 100 \%$, $100 \%$ and $91.8 \%$ respectively but the result was statistically insignificant with $\mathrm{P}$ value of 0.097 and 0.189 without and with binomial logistic regression analysis respectively.

Study by Jason D. Janniculi et al ${ }^{22}$ showed calcification in $12(35.3 \%)$ of 34 malignant nodules of which $5(41.7 \%)$ of 12 calcified malignant nodules had snow storm type of calcification which was present in $1(20 \%)$ of 5 calcified malignant nodules in present study. The study by Enrico papini et al ${ }^{20}$ showed that presence of microcalcification had the highest specificity for malignancy (95\%).But it had very low sensitivity $(29.0 \%)$.

\section{EVALUATION OF INTERNAL VASCULARITY}

In this study all 6 malignant nodules $(100 \%)$ had internal vascularity which was $<25 \%$ (grade I). whereas benign nodules were variable in internal vascularity. Twenty seven benign nodules $(48.2 \%)$ had no vascularity. Two benign nodules $(3.6 \%)$ had $51-75 \%$ internal vascularity. 7 of the 56 benign nodules $(12.5 \%)$ had vascularity of grade II (26-50\%). 20 benign nodules $(35.7 \%)$ had internal vascularity of grade I $(<25 \%)$.P-value: 0.027 .

As a single parameter to predict malignancy, internal vascularity of grade I had sensitivity, specificity, positive predictive value and negative predictive value of $100 \%, 64.3 \%, 23.1 \%$ and $100 \%$ respectively with $\mathrm{P}$ value of 0.004 . However after binomial logistic regressin analysis, $\mathrm{P}$ value was 1.000 .

Many studies in the past showed that greater the degree of internal vascularity, the more the likelihood of malignancy. However study carried out by Jason D. Janniculi et al ${ }^{22}$ showed that the increased internal vascularity was 
more common in benign nodules than in malignant nodules. In their study, 3 of $36(8.3 \%)$ benign nodules showed internal vascularity $>75 \%$ (grade 4 ), none of the malignant nodules in their study showed internal vascular flow $>50 \%$.only $20.6 \%$ malignant nodules showed internal vascular flow $>25 \% .69 .4 \%$ of benign and $64.7 \%$ of malignant nodules showed no internal vascular flow. The sensitivity and specificity of intranodular vascularity were $80.8 \%$ and $74.2 \%$ respectively.

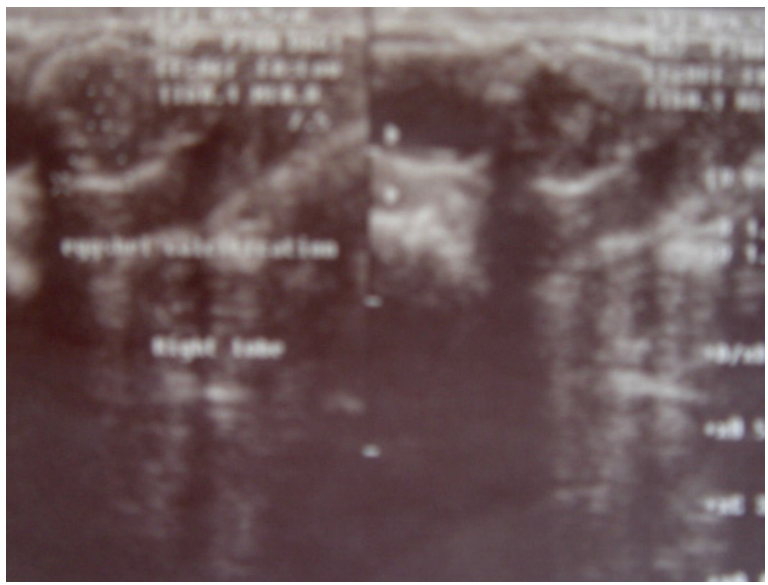

Figure 4: A solitary thyroid nodule with welldefined margin and eggshell calcification, a case of benign nodule

\section{CONCLUSION}

This study has shown that colloid goiter is the commonest benign diagnosis whereas papillary carcinoma is the commonest malignancy. Malignant nodules are solid or predominantly solid whereas cystic and predominantly cystic nodules are likely to be benign. Macrocalcification is not helpful to differentiate benign from malignant nodule. However snowstorm calcification makes a nodule likely to be malignant whereas egg shell calcification is characteristic for benign nodule.

\section{CONFLICT OF INTEREST}

None

\section{SOURCES OF FUNDING}

None

\section{REFERENCES}

1. Solbiati L, Charboneau JW, Osti V, James EM ,Hay ID.The Thyroid Gland. In:Rumack CM, Wilson SR, Charboneau JW,editors. Diagnostic Ultrasound, 3rd edition. St Louis,Elevier Mosby.volume 1, 2005:p735-770.

2. Rojeski MT, Gharib H. Nodular thyroid disease: Evaluation and management. $N$ Engl $J$ Med 1985;313:428-436. https://doi.org/10.1056/ $\underline{\text { NEJM198508153130707 }}$

3. Van Herle AJ, Rich P, Ljung B-ME et al. The thyroid nodule. Ann Intern Med 1992;96:221-232. https://doi.org/10.7326/0003-4819-96-2$\underline{221}$

4. Favus MJ, Schneider AB,Stachura ME,et al. Thyroid cancer occurring as a late consequence of head-and-neck irradiation: Evaluation of 1056 patients. $N$ Engl J Med 1976;294:1019-1025. ht tps://doi.org/10.1056/ NEJM197605062941901

5. Degroot LJ, Reily M, Pinnamenni K, et al. Retrospective and prospective study of radiation-induced thyroid disease. $A m \quad J \quad$ Med 1983;74:852-862 https://doi.org/10.1016/00029343(83)91077-X

6. Hegedüs L. The Thyroid Nodule. N Engl J Med 2004; 351:1764-1771. https://doi.org/10.1056/NEJMcp031436

7. Grebe SKG, Hay ID. Follicular cell-derived thyroid carcinoma. Cancer treat Res 1997; 89:91-140. https://doi.org/10.1007/978-1-4615-6355$\underline{66}$

8. Hennemann G. Non-toxic goiter.Clin Endocrinol Metab 1979; 8:167-179. https://doi.org/10.1016/S0300595X(79)80015-8 
9. Kerr L. High-resolution thyroid ultrasound: the value of color Doppler. Ultrasound $Q$ 1994; 12:21-43. https://doi.org/10.1097/00013644199412010-00002

10. Solbiati L, Cioffi V, Ballarati E. Ultrasonography of the neck. Radiol Clin North Am 1992;30:941-954. Available from: https://www.ncbi. nlm.nih.gov/pubmed/1518938 [Acessed 21st Dec 2015].

11. Muller HW, Schroder S, Schneider C et al. Sonographic tissue chacterization in thyroid gland diagnosis. Klin Wochenschr 1985;63:706-710. https://doi.org/10.1007/BF01733114

12. Schlumberger M-J,Filetti S, Hay ID. In: Nontoxic goiter and thyroid neoplasia. Larsen PR,Kronenberg HM,Melmed S,et al. (eds):Williams Textbook of Endocrinology, $10^{\text {th }}$ ed.Philadelphia,WB Saunders 2003:p 457-490.

13. Nel CJ,van Heerden JA, Goellner JR,James EM,et al. Anaplastic carcinoma of the thyroid :A clinicopathologic study of 82 cases. Mayo Clin Proc 1985; 60(1):51-58. https://doi.org/10.1016/S0025$\underline{6196(12) 65285-9}$

14. Kumar V,Cotran RS, Robbins SL. Diseases of the endocrine system, Basic Pathology.5th edition, W.B Saunders Company1992:p 643-680.

15. Jameson JL, Weetman AP. Disorders of the thyroid gland. In:Braunwald E,Fauci AS,Kasper D1,Hauser SL, Longo DL, Jameson JL,editors.Harrison's Principles of internal medicine, 15 th edition. Mc Graw Hill. Volume 2 2003:p 2063-2081.

16. Sadlor GP, Clarj OH.Vanherden JA, Farley DR. Thyroid and parathyroid. In: Schwartz SI, Shires GT, Spencer FC, DalyJM,.Fischer JE and Halloway AC, editors.Principles of Surgery.7th edition. Mc Graw Hill:p1661-1713.
17. Dudley N. The thyroid gland. In: Peter J Morris PJ. Malt DA,editors. Oxford Text Book of Surgery, International edition, Oxford University Press, volume 1, p731754.

18. Harach HR, Franssila KO, Wasenius V. Occult papillary carcinoma of the thyroid: a "normal" finding in Finland. Cancer 1985; 56:531-538. https://doi.org/10.1002/10970142(19850801)56:3<531::AIDCNCR2820560321>3.0.CO;2-3

19. Monchick JM, De Petris G, De Crea C. Occult papillary carcinoma of the thyroid presenting as cervical cyst. Surgery 2001;129:429-432. https://doi.org/10.1016/S00396060(01)60495-1

20. Papini E, Guglielmi R, Bianchini A, et al. Risk of malignancy in nonpalpable thyroid nodules: predictive value of ultrasound and color-Doppler features. $J$ Clin Endocrinol Metab 2002; 87:1941-1946. https://doi.org/10.1210/jcem.87.5.8504

21. Kim E, Park CS, Chung WY, et al. New sonographic criteria for recommending fine-needle aspiration biopsy of nonpalpable solid nodules of the thyroid. AJR Am J Roentgenol 2002; 178:687-691. https://doi.org/10.2214/ajr.178.3.1780687

22. Iannuccilli JD, Cronan JJ, and Monchik JM. Risk for Malignancy of Thyroid Nodules as Assessed by Sonographic Criteria: The need for biopsy. $J$ Ultrasound Med 2004; 23(11):1455-1464. $\mathrm{https:// \textrm {doi } . 0 \mathrm { rg } / 1 0 . 7 8 6 3 /}$ jum.2004.23.11.1455

23. Frates $\mathrm{MC}$, Benson $\mathrm{CB}$, Doubilet PM et al. Prevalence and Distribution of Carcinoma in Patients with Solitary and Multiple Thyroid Nodules on Sonography. $J$ Clin Endocrinol Metab 2006 Sep; 91(9):3411-17. https://doi.org/10.1210/jc.2006-0690 